\title{
Drying process, storage conditions, and time alter the biochemical composition and bioactivity of the anti-greenhouse seaweed Asparagopsis taxiformis
}

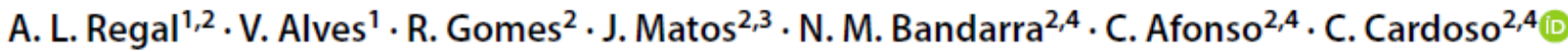

\begin{abstract}
The Azorean red seaweed Asparagopsis taxiformis may be used in human and animal diets. This seaweed is deemed to reduce the large production of methane-a major greenhouse gas-by ruminant digestion. Seaweed producers, however, have difficulties in ensuring a reliable and similar product throughout all year and in different years. Changes in biochemical composition and bioactivity are caused not only by natural variability, but also by the particular drying process, storage conditions, and storage time. Regarding the drying process, oven-dried samples had a lower EPA content, $1.9 \pm 0.2 \%$ of the total FAs, than freeze-dried samples, $8.6 \pm 1.7 \%$. The same occurred with the phenolic contents and particularly with the ethanolic extracts. ABTS antioxidant activity results showed freeze-drying as advantageous. With respect to storage temperature, anti-inflammatory activity was higher in A. taxiformis at room temperature after three month storage. Moreover, EPA content in freeze-dried samples decreased to $0.3-1.0 \%$ after three month storage. Phenolic content in the ethanolic extracts also declined over storage time. In the case of aqueous extracts, however, variation was in the opposite direction. Antioxidant activity as measured by ABTS showed for almost all samples and types of extracts an increasing trend over time: from $0.26-1.75$ to $0.75-4.40 \mathrm{mmol}$ Trolox Eq/100 g dw. Anti-inflammatory activity increased over time from $<30 \% \mathrm{COX}-2$ inhibition at the beginning of the trial to $>30 \%$ COX-2 inhibition after three month storage. Therefore, there is a relevant bioactive potential in A. taxiformis and the drying process and storage conditions and time affect this potential.
\end{abstract}

Keywords Asparagopsis taxiformis $\cdot$ Drying process $\cdot$ Storage conditions and time $\cdot$ Fatty acid profile $\cdot$ Antioxidant activity · Anti-inflammatory activity

\section{Abbreviations}

$\mathrm{AA} \mathrm{Eq}$

Ascorbic acid equivalent

ABTS 2,2'-Azino-bis(3-ethylbenzothiazoline-6-sulphonic acid

ARA Arachidonic acid

C. Cardoso

carlos_1_cardoso@hotmail.com

1 LEAF, Linking Landscape, Environment, Agriculture And Food, Instituto Superior de Agronomia, Universidade de Lisboa, Tapada da Ajuda, 1349-017 Lisbon, Portugal

2 Division of Aquaculture and Upgrading (DivAV), Portuguese Institute for the Sea and Atmosphere (IPMA, IP), Avenida Alfredo Magalhães Ramalho, 6, 1495-006 Lisbon, Portugal

3 Faculdade de Ciências da Universidade de Lisboa, Campo Grande, 16, 1749-016 Lisbon, Portugal

4 CIIMAR, Interdisciplinary Centre of Marine and Environmental Research, University of Porto, Rua dos Bragas 289, 4050-123 Porto, Portugal

$\begin{array}{ll}\text { COX-2 } & \text { Cyclooxygenase-2 } \\ \text { DHA } & \text { Docosahexaenoic acid } \\ \text { DMSO } & \text { Dimethyl sulphoxide } \\ \text { DPPH } & \text { 2,2-Diphenyl-1-picrylhydrazyl } \\ \text { ELISA } & \text { Enzyme-Linked Immunosorbent Assay } \\ \text { EPA } & \text { Eicosapentaenoic acid } \\ \text { F } & \text { Freezing temperature } \\ \text { FA } & \text { Fatty acid } \\ \text { FAME } & \text { Fatty acid methyl ester } \\ \text { GA } & \text { Gallic acid } \\ \text { GAE } & \text { Gallic acid equivalent } \\ \text { HSD } & \text { Honestly significant difference } \\ \text { L } & \text { Freeze-dried samples } \\ \text { MUFA } & \text { Monounsaturated fatty acid } \\ \text { O } & \text { Oven-dried samples } \\ \text { PUFA } & \text { Polyunsaturated fatty acid } \\ \text { R } & \text { Room temperature } \\ \text { SFA } & \text { Saturated fatty acid } \\ \text { TFC } & \text { Total flavonoid content }\end{array}$


TPC

Total content of phenolic compounds

Trolox Eq Trolox equivalent

$\omega 3$ PUFA Omega-3 polyunsaturated fatty acid

$\omega 6$ PUFA Omega-6 polyunsaturated fatty acid

\section{Introduction}

The seaweed Asparagopsis taxiformis is a medium-sized red macroalgal species belonging to the order Bonnemaisoniales and family Bonnemaisoniaceae that has a broad global distribution, being found particularly in tropical and sub-tropical coastal marine ecosystems $[1,2]$. This species is typically found in the Pacific and Indo-Pacific region, including Mexico, Hawaii, California, China, Japan, and Australia. It is now spreading in the Atlantic Ocean, notably in the Azores Archipelago, and is also found in the Mediterranean Sea [2]. It is an edible seaweed that is consumed in China and India.

Brominated compounds usual in the genus Asparagopsis have an effective inhibitory action on archaebacterial metabolism and growth of methanogenic archaea in the case of $A$. taxiformis [3]. This finding is particularly relevant since, according to Roque et al. (2019) [3], the incorporation of 5\% A. taxiformis organic matter in dairy cattle feed may lead to reductions of methane production in the rumen surpassing $90 \%$. The incorporation of $A$. taxiformis into feed seems to be a promising strategy in the fight against climate change induced by greenhouse gases, given that methane emissions from cows represent a large share of total global methane emissions and that this gas is long-term a more powerful greenhouse gas than carbon dioxide [4].

Regarding other possible applications and properties, there are few studies on this particular red seaweed species. Studies on other red seaweeds have shown that they synthesize a wide variety of bioactive metabolites, including polysaccharides, proteins, polyunsaturated fatty acids (PUFA), polyphenols and some pigments, which, in turn, underlie biological activities, such as antioxidant, anti-diabetic, anti-inflammatory, anti-tumor activity, and many others [5, 6]. A seaweed species belonging to the same genus, A. armata, was shown to have a substantial anti-inflammatory activity as measured by inhibition of phospholipase A2 activity [7]. Concerning A. taxiformis itself, there are two important studies on bioactives and properties [8, 9]. Nunes et al. (2017) [8] compared $A$. taxiformis with other red seaweeds as well as green and brown seaweeds and found out that its biomass is relatively rich in fibre and matricial polysaccharides and it contains significant levels of chlorophyll $a(28.8 \pm 3.2 \mathrm{mg} / 100 \mathrm{~g}$ $\mathrm{dw})$, carotenoids $(13.1 \pm 2.6 \mathrm{mg} / 100 \mathrm{~g} \mathrm{dw})$, and phenolic compounds $(57.6 \pm 3.9 \mathrm{mg} \mathrm{GAE} / 100 \mathrm{~g} \mathrm{dw})$. Within the group of carotenoids, fucoxanthin has been identified in A. taxiformis [9]. The FA profile of A. taxiformis was also analysed, but only very low levels of the bioactive eicosapentaenoic acid (EPA, 20:5 $\omega 3$ ) were determined [9]. Mellouk et al. (2017) [10] also reported low EPA content in the biomass of $A$. taxiformis, but quantified a large share of another bioactive $\omega 3$ PUFA, docosahexaenoic acid (DHA, 22:6 63 ), exceeding 30\% of total FAs. EPA and DHA intakes are associated with decreased morbidity and mortality from cardiovascular and other diseases [11]. In addition, EPA has been claimed to strengthen the anti-inflammatory properties of high-density lipoprotein, among other effects [12].

It is well known that seaweeds have a high percentage of moisture, often exceeding $90 \%$ of the wet weight, thus making their biomass highly perishable [13, 14]. Hence, it is critically important that appropriate drying and storage conditions are applied to preserve biomass quality and ensure product safety. Typically, in the industry, algal biomass is dried and stored at a temperature between 0 and $4{ }^{\circ} \mathrm{C}$ or approximately $-18{ }^{\circ} \mathrm{C}$, depending on whether it is dry or semi-dry, respectively $[13,15]$. Applied methods include simple air drying and/or sundrying or more expensive and/or innovative methods, such as drying in hot air ovens and freeze-drying. All these techniques have advantages and drawbacks [15].

Drying methods are effective techniques for moisture removal, but several studies have shown that the temperatures endured by the algal biomass during these processes may cause significant changes in its properties [16]. Namely, Gupta et al. (2011) [13] analysed the effect of drying on the total content of phenolic compounds (TPC) and flavonoids (TFC) and on the antioxidant activity of the brown seaweed Himanthalia elongata. For this purpose, different drying temperatures $\left(25,30,35\right.$, and $\left.40{ }^{\circ} \mathrm{C}\right)$ were applied for $24 \mathrm{~h}$ in a hot air oven. For all temperatures, a reduction in TPC and TFC as well as a decrease in antioxidant activity in comparison to fresh biomass was observed [13]. Other studies [14, 17] have been done on various seaweed species and have indicated significant alterations of composition and bioactivity as a result of different drying and storage conditions. Similar data is not found for A. taxiformis, which makes this a relevant knowledge gap, especially taking into account the possible future relevance of this species.

Therefore, the purpose of this work was threefold: to assess the effect of the drying process (oven-drying at $60{ }^{\circ} \mathrm{C}$ for $72 \mathrm{~h}$ vs freeze-drying at $-40{ }^{\circ} \mathrm{C}$ and $4 \times 10^{-4} \mathrm{mbar}$ for $48 \mathrm{~h}$ ); storage temperature (room temperature, $15 \pm 5^{\circ} \mathrm{C}$ vs frozen storage, $-20^{\circ} \mathrm{C}$ ); and storage time ( $0-3$ months) on relevant parameters of $A$. taxiformis biomass. Accordingly, this study entailed the determination of the FA profile, total phenolic content, and relevant bioactivities of the algal biomass as a function of the three tested variables. 


\section{Materials and methods}

\section{Human and animal rights}

Not relevant in this study.

\section{Seaweed source, collection, and preparation}

The studied seaweed species was Asparagopsis taxiformis. This is a marketed red seaweed whose taxonomic identification was guaranteed by the Portuguese producer company, seaExpert (Faial, Azores, Portugal). Specific traits that led to this identification were its dark red colour and a creeping base with rigid upright branches, being each branch covered by many fuzzy soft branchlets that get shorter towards the top. Moreover, previous identical seaweed samples of the same area had been identified by sequencing the $5^{\prime}$ end of the mitochondrial cytochrome c oxidase gene (COI-5'), the official barcode suggested for red algae [18].

This seaweed originated from the Azores islands (Portugal, located in the mid-North Atlantic), more specifically, Faial Island, being collected from the wild (coordinates: $38^{\circ} 31^{\prime} 24.0^{\prime \prime} \mathrm{N}$ and $28^{\circ} 38^{\prime} 34$. $^{\prime \prime} \mathrm{W}$, at $5 \mathrm{~m}$ depth and water temperature $16{ }^{\circ} \mathrm{C}$ by an apnea diver, which carried out the collection by total removal of the specimens, including the seaweed holdfast) in the morning of 2nd November 2018 (Autumn). The fresh frond seaweed biomass was immediately frozen $\left(-20^{\circ} \mathrm{C}\right)$ after harvest, packaged in plastic bags, and sent to the IPMA laboratory in Lisbon. Afterwards, $5 \mathrm{~kg}$ of frozen seaweed was kept stored at $-20{ }^{\circ} \mathrm{C}$ until further treatment.

\section{Seaweed drying and storage}

The frozen biomass of $A$. taxiformis was subjected to two alternative drying techniques: oven-drying and freeze-drying. Accordingly, the frozen seaweed blocks were cut into pieces and approximately $2.7 \mathrm{~kg}$ were dried in an oven, while approximately $2 \mathrm{~kg}$ were dried in a freeze-drier. Oven-drying was carried out at $60{ }^{\circ} \mathrm{C}$ for $72 \mathrm{~h}$ in a Memmert equipment without air circulation (Memmert $\mathrm{GmbH}+\mathrm{Co} . \mathrm{KG}$, Schwabach, Germany). Freeze-drying (after $6 \mathrm{~h}$ at $-80{ }^{\circ} \mathrm{C}$ ) was performed at $-40^{\circ} \mathrm{C}$ and a pressure of $4 \times 10^{-4} \mathrm{mbar}$ for $48 \mathrm{~h}$ in a Heto Power Dry LL3000 freeze-dryer (Thermo Fisher Scientific, Waltham, MA, USA). After drying, samples were ground at room temperature in a Grindomix GM 200 mill (Retsch, Haan, Germany) to $100-500 \mu \mathrm{m}$ particles with 3 cycles of $5 \mathrm{~s}$ at $3000 \mathrm{rpm}$ and 2 cycles of $5 \mathrm{~s}$ at $5000 \mathrm{rpm}$ and then packaged in sealed bags with some vacuum (200 mbar).
Afterwards, both oven-dried $(\mathrm{O})$ and freeze-dried (L, lyophilized) samples were stored at two alternative temperatures: room temperature, $15 \pm 5{ }^{\circ} \mathrm{C}(\mathrm{OR} \& \mathrm{LR})$ and freezing temperature, $-20{ }^{\circ} \mathrm{C}$ (OF \& LF), for three months. The former temperature conditions were chosen to replicate the storage conditions used by industry in Portugal (absence of temperature control and, consequently, typical room temperatures oscillating between 10 and $20^{\circ} \mathrm{C}$ ). The latter temperature conditions correspond to a situation in which changes during storage time would be expected to be minimal.

At the beginning of the storage study (OR0, OF0, LR0 \& LF0) and at every month (OR1, OF1, LR1 \& LF1; OR2, OF2, LR2 \& LF2) until the end (OR3, OF3, LR3 \& LF3), a set of relevant parameters of the A. taxiformis biomass were determined. The overall experimental scheme is presented in Fig. 1.

\section{Proximate composition and fibre content}

The moisture and ash contents were determined according to Association of Official Analytical Chemists (AOAC) methods [19]. The protein level was quantified according to the Dumas method [20]. Crude lipid content was determined following the Folch extraction method [21]. Fibre content was determined through an enzymatic procedure on the basis of the K-TDFR-100A/K-TDFR-200A Megazyme Kit (Megazyme, Bray, Ireland). First, $1.000 \pm 0.005 \mathrm{~g}$ of sample was weighed, $40 \mathrm{ml}$ of MES-TRIS blend buffer $(\mathrm{pH}$ 8.2) was added, and the resulting mixture was stirred. Afterwards, $50 \mu \mathrm{l}$ of thermostable $\alpha$-amylase solution was added and the dispersion-enzyme mixture was incubated with agitation at 98-100 ${ }^{\circ} \mathrm{C}$ for $30 \mathrm{~min}$. Then, mixture was cooled to $60{ }^{\circ} \mathrm{C}$. For second incubation, $100 \mu \mathrm{l}$ of protease solution was added and attained mixture was left at $60 \pm 1{ }^{\circ} \mathrm{C}$ for $30 \mathrm{~min}$ with agitation. Afterwards, $5 \mathrm{ml}$ of $0.561 \mathrm{~N} \mathrm{HCl}$ solution was added with constant agitation to the mixture for a final $\mathrm{pH}$ in the 4.1-4.8 interval. Third incubation was initiated with the addition of $200 \mu \mathrm{l}$ of amyloglucosidase solution and required $30 \mathrm{~min}$ at $60 \pm 1{ }^{\circ} \mathrm{C}$ with agitation. The final mixture was filtered through a Gooch fritted crucible (previously weighed with a layer of Celite ${ }^{\circledR}$ ) and residue was washed with $70{ }^{\circ} \mathrm{C}$ distilled water. The attained filtrate was kept in a previously weighed container for the determination of soluble fibre. Residue was then washed with $10 \mathrm{ml}$ of $95 \%$, v/v, ethanol and $10 \mathrm{ml}$ of acetone. The residue-containing Gooch fritted crucible was dried overnight in an oven at $103{ }^{\circ} \mathrm{C}$. Next day, the crucible was weighed for the calculation of insoluble fibre. Regarding soluble fibre, the container with filtrate was weighed for determining filtrate weight, which was used to determine required volume of $60{ }^{\circ} \mathrm{C} 95 \%$, v/v, ethanol according to a $1 \mathrm{~g}: 4 \mathrm{ml} \mathrm{w}: \mathrm{v}$ proportion. After adding $60{ }^{\circ} \mathrm{C}$ $95 \%, v / v$, ethanol to the filtrate, the mixture was left at room temperature for $1 \mathrm{~h}$. Afterwards, the mixture was filtered 
Fig. 1 Experimental design of the A. taxiformis study of quality as a function of drying conditions (oven-drying $v s$ freezedrying), storage conditions (room temperature, $15 \pm 5^{\circ} \mathrm{C}$ vs frozen storage, $-20^{\circ} \mathrm{C}$ ), and storage time ( $t$ : 0 month-1 mon th-2 month-3 month). $L$ Freezedried samples, $O$ Oven-dried samples, $R$ Room temperature, and $F$ Freezing temperature

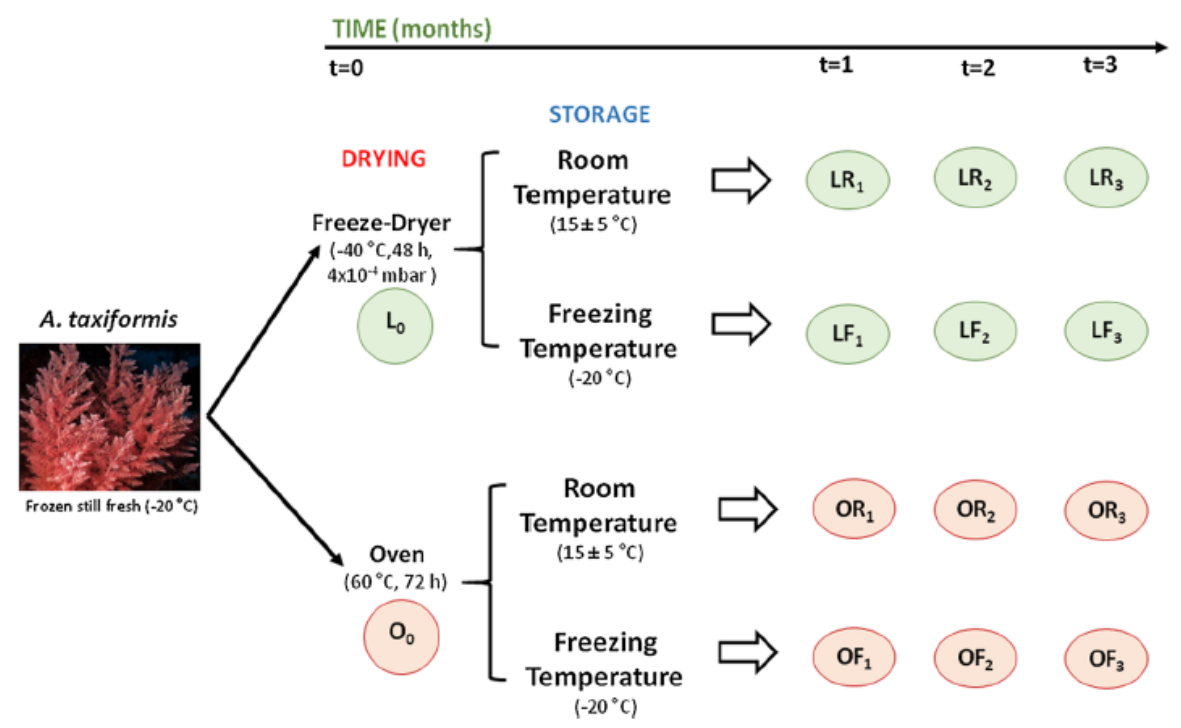

through a Gooch fritted crucible (previously weighed with a layer of Celite $($ ) and remaining particles in the precipitation container were transferred to the crucible with $78 \%$, $\mathrm{v} / \mathrm{v}$, ethanol. Residue was then washed twice with $15 \mathrm{ml}$ of $78 \%$, v/v, ethanol, $15 \mathrm{ml}$ of $95 \%$, v/v, ethanol, and $15 \mathrm{ml}$ of acetone. Following steps were done as described for the insoluble fibre. The contents of insoluble and soluble fibre were corrected through subtraction of protein and ash contents in the residues $[19,20]$. Total fibre content was the sum of the insoluble and soluble fibre contents. Analyses were done in duplicate.

\section{Fatty acid profile}

Fatty acid methyl esters (FAMEs) were prepared from ovendried and freeze-dried seaweed by acid-catalysed transesterification using the methodology described by Bandarra et al. (1997) [22]. The samples were applied to a DB-WAX (Agilent Technologies, Santa Clara, USA) capillary column (film thickness, $0.25 \mu \mathrm{m}, 30 \mathrm{~m} \times 0.25 \mathrm{~mm}$ i.d.) integrated into a Varian Star $3800 \mathrm{CP}$ gas chromatograph (Walnut Creek, CA, USA), which was equipped with an auto sampler with a split injector (100:1) and a flame ionization detector, both at $250{ }^{\circ} \mathrm{C}$. The separation of the FAMEs was performed using helium as the carrier gas and with a temperature programme for the column starting at $180^{\circ} \mathrm{C}$ and increasing to $200{ }^{\circ} \mathrm{C}$ at $4{ }^{\circ} \mathrm{C} / \mathrm{min}$, holding for $10 \mathrm{~min}$ at $200^{\circ} \mathrm{C}$, heating to $210^{\circ} \mathrm{C}$ at the same rate, and holding at this temperature for $14.5 \mathrm{~min}$. The FAMEs were identified by comparing their retention time with those of several Sigma-Aldrich standards (PUFA3, Menhaden oil, and PUFA-1, marine source from Supelco Analytical). This analysis was done in triplicate.

\section{Total polyphenol content}

The phenolic compounds were extracted using a selected solvent. Water and ethanol 96\%, w/w, were chosen from among different safe and environmentally acceptable solvents as being the most effective. Accordingly, the selected solvent was added to the oven-dried and freeze-dried seaweed biomass, thus matching the extracts used in the assessment of the antioxidant potential (see "Antioxidant activity as measured by DPPH method" Section), and the total polyphenol content was determined by the Singleton and Rossi method using Folin-Ciocalteu reagent [23]. Gallic acid (GA) was used as a standard and the phenolic content was expressed as gallic acid equivalents ( $\mathrm{mg} \mathrm{GAE} / 100 \mathrm{~g}$ ) according to a gallic acid calibration curve (Sigma, Steinheim, Germany). This analysis was done in triplicate.

\section{Antioxidant activity as measured by DPPH method}

The antioxidant activity was measured by determining the radical scavenging activity using 2,2-diphenyl-1-picrylhydrazyl (DPPH) [24]. To prepare the extracts, approximately $1.25 \mathrm{~g}$ of oven-dried and freeze-dried seaweed biomass was weighed and homogenized with $25 \mathrm{ml}$ of water or ethanol 96\%, w/w using a model Polytron PT 6100 homogenizer (Kinematica, Luzern, Switzerland) at a velocity of $30,000 \mathrm{rpm}$ for $1 \mathrm{~min}$, and agitated for $18 \mathrm{~h}$ on an orbital shaker. Following centrifugation (at $5000 \times \mathrm{g}$ at room temperature during $20 \mathrm{~min}$ ), the supernatant was collected through a filter to a final volume of $25 \mathrm{ml}$. A $1 \mathrm{ml}$ volume of the extract was prepared in triplicate for each sample and $2 \mathrm{ml}$ of DPPH (Sigma, Steinheim, Germany) in $0.15 \mathrm{mM}$ methanolic solution was added and thoroughly mixed. After 
30 min of incubation at room temperature in the dark, the absorbance was measured at $517 \mathrm{~nm}$ in a Helios Alpha model (Unicam, Leeds, UK) UV/visible light spectrophotometer. Either water or ethanol $96 \%$, w/w, was used as the blank.

The radical scavenging activity was calculated using the following formula:

$\%$ Inhibition $=(\mathrm{A} 0-$ Asample $) / \mathrm{A} 0 \times 100$

where A0 - Absorbance of the blank, Asample - Absorbance of the sample.

On the basis of the ascorbic acid calibration curve, results were then expressed in mg of ascorbic acid equivalents (AA Eq) per $100 \mathrm{~g}$ of seaweed dry weight. This analysis was done in triplicate.

\section{Antioxidant activity as measured by ABTS method}

The ABTS (2,2'-azino-bis(3-ethylbenzothiazoline-6-sulphonic acid)) radical scavenging activity was determined using the method described by Re et al. (1999) [25]. The ABTS radical scavenging activity of the samples was expressed as a percentage of inhibition as follows:

$\%$ Inhibition $=(\mathrm{A} 0-$ Asample $) / \mathrm{A} 0 \times 100$

where A0 - Absorbance of the blank, Asample - Absorbance of the sample.

On the basis of a trolox calibration curve, results were then expressed in mmol of trolox equivalents (Trolox Eq) per $100 \mathrm{~g} \mathrm{dw}$ of seaweed. This analysis was done in triplicate.

\section{Anti-inflammatory activity}

The anti-inflammatory activities of the seaweed A. taxiformis were determined in ethanol extracts obtained from approximately $200 \mathrm{mg}$ of sun-dried and freeze-dried seaweed homogenized with $2 \mathrm{ml}$ of ethanol 96\%, w/w, using a model Polytron PT6100 homogenizer (Kinematica, Luzern, Switzerland) at a velocity of $30,000 \mathrm{rpm}$ for $1 \mathrm{~min}$. The extracts were subjected to heat treatment $\left(80^{\circ} \mathrm{C}\right.$ during $\left.1 \mathrm{~h}\right)$ and then centrifuged $\left(3,000 \times \mathrm{g}\right.$ at $4{ }^{\circ} \mathrm{C}$ during $\left.10 \mathrm{~min}\right)$. The supernatant was collected and the solvent was evaporated using a vacuum rotary evaporator at a water bath temperature of $65^{\circ} \mathrm{C}$. The residue was directly dissolved in $100 \%$ dimethyl sulphoxide (DMSO) to prepare a stock solution with a concentration of $10 \mathrm{mg} / \mathrm{ml}$. The extract was tested at $1 \mathrm{mg} / \mathrm{ml}$ using a commercial cyclooxygenase (COX) inhibitory screening assay kit, Cayman test kit-560131 (Cayman Chemical Company, Ann Arbor, MI, USA). The COX-2 inhibitor screening assay directly measures the amount of prostaglandin F2 $\alpha$ generated from arachidonic acid (ARA, $20: 4 \omega 6)$ in the cyclooxygenase reaction. A volume of $10 \mu \mathrm{l}$ each of test extract or DMSO was used. The reaction was initiated by addition of $10 \mu 110 \mathrm{mM}$ ARA and each reaction tube was incubated at $37{ }^{\circ} \mathrm{C}$ for $2 \mathrm{~min}$. The reaction was terminated by addition of $50 \mu \mathrm{l} \mathrm{N} \mathrm{HCl}$ and saturated stannous chloride. Assays were performed using 100 units of human recombinant COX-2. An aliquot was removed and the prostanoid produced was quantified spectrophotometrically $(412 \mathrm{~nm})$ via enzyme immunoassay (ELISA) after $18 \mathrm{~h}$ incubation, washing, addition of Ellman's reagent, and further $90 \mathrm{~min}$ incubation. The results were expressed as the percentage of COX-2 inhibition. For this methodology, four replicates were analysed.

\section{Statistical analysis}

To test the normality and the homogeneity of the data variance, the Kolmogorov-Smirnov test and Cochran's C-test were used, respectively. The data were analysed by one-way and factorial ANOVA distributions using Tukey's HSD to determine the difference in the constituent contents and in the biological activities between drying treatments, storage temperature, and storage time. For the anti-inflammatory activity, owing to the different numbers of replicates for each sample, a factorial ANOVA distribution was applied in combination with a Tukey Unequal N HSD. For all the statistical tests, the significance level $(\alpha)$ was 0.05 . All the data analyses were performed using STATISTICA 7 (Stat-sof, Inc. USA, 2003). Additionally, the possibility of correlations between EPA and total polyphenol content or bioactivities (antioxidant and anti-inflammatory) as well as between total polyphenol content and bioactivities was tested by the application of linear regression (least quadratic method).

\section{Results}

\section{Proximate composition and fibre content}

The proximate composition and insoluble, soluble, and total fibre content values are presented in Table 1.

At the beginning of the study, it was observed a higher moisture level in the freeze-dried A. taxiformis than in the oven-dried seaweed. This difference was maintained throughout storage time. Storage temperature had only an effect after three month storage, leading to higher moisture levels at room temperature. Regarding ash content, neither time nor temperature produced a variation. Freeze-dried samples presented consistently lower ash contents. Variability in protein content was even more reduced than in ash content. Indeed, there was only a consistent higher protein content in freeze-dried samples at the initial point $(t=0$ month). Concerning lipid content, values were always low, but freeze-dried A. taxiformis displayed values slightly 
Table 1 Proximate composition and insoluble, soluble, and total fibre contents (in \% dry weight) of Asparagopsis taxiformis subjected to different drying processes and storage conditions at different times of the storage stability experiment

\begin{tabular}{|c|c|c|c|c|c|}
\hline \multirow[t]{2}{*}{ Sample } & \multirow[t]{2}{*}{$\begin{array}{l}\text { Time } \\
\text { (month) }\end{array}$} & \multicolumn{4}{|c|}{$\begin{array}{l}\text { Proximate composition and insoluble, soluble, and total fibre contents } \\
(\% \mathrm{dw})\end{array}$} \\
\hline & & OR & OF & LR & LF \\
\hline \multirow[t]{4}{*}{ Moisture } & 0 & $2.7 \pm 0.0^{\mathrm{aw}}$ & $2.7 \pm 0.0^{\mathrm{aw}}$ & $5.6 \pm 0.0^{\mathrm{bw}}$ & $5.6 \pm 0.0^{\mathrm{bw}}$ \\
\hline & 1 & $2.8 \pm 0.1^{\mathrm{aw}}$ & $2.6 \pm 0.1^{\mathrm{aw}}$ & $5.6 \pm 0.0^{\mathrm{bw}}$ & $5.7 \pm 0.2^{\mathrm{bw}}$ \\
\hline & 2 & $3.0 \pm 0.2^{\mathrm{aw}}$ & $2.8 \pm 0.0^{\mathrm{aw}}$ & $5.9 \pm 0.1^{\mathrm{bw}}$ & $5.7 \pm 0.2^{\mathrm{bw}}$ \\
\hline & 3 & $4.3 \pm 0.1^{\mathbf{b x}}$ & $2.5 \pm 0.0^{\mathrm{aw}}$ & $6.2 \pm 0.0^{\mathrm{dx}}$ & $5.0 \pm 0.0^{\mathrm{cx}}$ \\
\hline \multirow[t]{4}{*}{ Ash } & 0 & $48.7 \pm 0.0^{\mathrm{aw}}$ & $48.7 \pm 0.0^{\mathrm{aw}}$ & $44.4 \pm 0.1^{\mathrm{bw}}$ & $44.4 \pm 0.1^{\mathrm{bw}}$ \\
\hline & 1 & $48.4 \pm 0.3^{\mathrm{aw}}$ & $48.7 \pm 0.0^{\mathrm{aw}}$ & $44.3 \pm 0.1^{\mathrm{bw}}$ & $44.4 \pm 0.0^{\mathrm{bw}}$ \\
\hline & 2 & $47.6 \pm 0.5^{\mathrm{aw}}$ & $48.4 \pm 0.3^{\text {aw }}$ & $45.1 \pm 0.8^{\mathrm{bw}}$ & $45.0 \pm 0.5^{\mathrm{bw}}$ \\
\hline & 3 & $47.3 \pm 0.7^{\mathrm{aw}}$ & $49.5 \pm 0.6^{\mathrm{aw}}$ & $45.6 \pm 0.5^{\mathrm{bw}}$ & $45.4 \pm 0.1^{\mathrm{bw}}$ \\
\hline \multirow[t]{4}{*}{ Protein } & 0 & $19.7 \pm 0.4^{\mathrm{aw}}$ & $19.7 \pm 0.4^{\text {aw }}$ & $20.8 \pm 0.2^{\mathrm{bw}}$ & $20.8 \pm 0.2^{\mathrm{bw}}$ \\
\hline & 1 & $19.3 \pm 0.8^{\mathrm{aw}}$ & $19.0 \pm 0.2^{\mathrm{aw}}$ & $20.8 \pm 0.0^{\mathrm{bw}}$ & $20.3 \pm 0.5^{\text {abw }}$ \\
\hline & 2 & $19.3 \pm 0.6^{\mathrm{aw}}$ & $19.3 \pm 0.6^{\text {aw }}$ & $19.7 \pm 0.1^{\mathrm{aw}}$ & $20.2 \pm 0.8^{\mathrm{aw}}$ \\
\hline & 3 & $18.7 \pm 0.1^{\mathrm{aw}}$ & $18.6 \pm 0.2^{\mathrm{aw}}$ & $19.7 \pm 0.5^{\mathrm{aw}}$ & $19.6 \pm 0.5^{\mathrm{aw}}$ \\
\hline \multirow[t]{4}{*}{ Lipid } & 0 & $1.5 \pm 0.2^{\mathrm{aw}}$ & $1.5 \pm 0.2^{\mathrm{aw}}$ & $3.4 \pm 0.3^{\mathrm{bw}}$ & $3.4 \pm 0.3^{\mathrm{bw}}$ \\
\hline & 1 & $1.3 \pm 0.4^{\mathrm{aw}}$ & $1.4 \pm 0.6^{\mathrm{aw}}$ & $3.0 \pm 0.8^{\mathrm{bw}}$ & $3.5 \pm 0.4^{\mathrm{bw}}$ \\
\hline & 2 & $1.3 \pm 0.1^{\mathrm{aw}}$ & $1.7 \pm 0.0^{\mathrm{aw}}$ & $2.6 \pm 0.5^{\mathrm{abw}}$ & $2.9 \pm 0.9^{\mathrm{bw}}$ \\
\hline & 3 & $1.1 \pm 0.2^{\mathrm{aw}}$ & $2.0 \pm 0.7^{\mathrm{abw}}$ & $2.8 \pm 0.3^{\mathrm{abw}}$ & $3.3 \pm 0.4^{\mathrm{bw}}$ \\
\hline \multirow[t]{4}{*}{ Insoluble fibre } & 0 & $15.3 \pm 0.5^{\mathrm{aw}}$ & $15.3 \pm 0.5^{\text {aw }}$ & $14.9 \pm 0.6^{\mathrm{aw}}$ & $14.9 \pm 0.6^{\mathrm{aw}}$ \\
\hline & 1 & $16.0 \pm 0.3^{\mathrm{aw}}$ & $16.0 \pm 0.1^{\mathrm{aw}}$ & $15.2 \pm 0.9^{\mathrm{aw}}$ & $15.5 \pm 0.1^{\mathrm{aw}}$ \\
\hline & 2 & $15.2 \pm 0.5^{\mathrm{aw}}$ & $15.4 \pm 0.7^{\text {aw }}$ & $14.9 \pm 0.4^{\mathrm{aw}}$ & $15.8 \pm 1.0^{\mathrm{aw}}$ \\
\hline & 3 & $15.5 \pm 0.7^{\mathrm{aw}}$ & $15.8 \pm 0.1^{\mathrm{aw}}$ & $15.1 \pm 0.4^{\mathrm{aw}}$ & $15.7 \pm 0.6^{\mathrm{aw}}$ \\
\hline \multirow[t]{4}{*}{ Soluble fibre } & 0 & $4.9 \pm 0.1^{\mathrm{aw}}$ & $4.9 \pm 0.1^{\mathrm{aw}}$ & $5.2 \pm 0.4^{\mathrm{aw}}$ & $5.2 \pm 0.4^{\mathrm{aw}}$ \\
\hline & 1 & $4.8 \pm 0.3^{\text {aw }}$ & $5.1 \pm 0.2^{\text {aw }}$ & $4.9 \pm 0.0^{\mathrm{aw}}$ & $4.9 \pm 0.6^{\mathrm{aw}}$ \\
\hline & 2 & $4.6 \pm 0.5^{\mathrm{aw}}$ & $5.3 \pm 0.9^{\mathrm{aw}}$ & $5.1 \pm 0.6^{\mathrm{aw}}$ & $4.6 \pm 1.1^{\mathrm{aw}}$ \\
\hline & 3 & $4.6 \pm 0.1^{\mathrm{aw}}$ & $4.9 \pm 0.2^{\text {aw }}$ & $4.9 \pm 0.7^{\text {aw }}$ & $5.0 \pm 0.1^{\mathrm{aw}}$ \\
\hline \multirow[t]{4}{*}{ Total fibre } & 0 & $20.2 \pm 0.5^{\mathrm{aw}}$ & $20.2 \pm 0.5^{\text {aw }}$ & $20.1 \pm 0.7^{\mathrm{aw}}$ & $20.1 \pm 0.7^{\mathrm{aw}}$ \\
\hline & 1 & $20.8 \pm 0.5^{\mathrm{aw}}$ & $21.1 \pm 0.3^{\text {aw }}$ & $20.1 \pm 1.0^{\mathrm{aw}}$ & $20.4 \pm 0.6^{\mathrm{aw}}$ \\
\hline & 2 & $19.8 \pm 0.7^{\mathrm{aw}}$ & $20.7 \pm 1.1^{\mathrm{aw}}$ & $20.0 \pm 0.7^{\mathrm{aw}}$ & $20.4 \pm 1.3^{\mathrm{aw}}$ \\
\hline & 3 & $20.1 \pm 0.9^{\mathrm{aw}}$ & $20.7 \pm 0.2^{\text {aw }}$ & $20.0 \pm 0.9^{\mathrm{aw}}$ & $20.7 \pm 0.8^{\mathrm{aw}}$ \\
\hline
\end{tabular}

Values are presented as the average \pm standard deviation. Different lowercase letters (a-d) within a row correspond to significant differences $(p<0.05)$ between the drying and storage conditions. Different lowercase letters $(\mathrm{w}-\mathrm{z})$ within a column correspond to significant differences $(p<0.05)$ over storage time for each type of extract

$L$ Freeze-dried samples, $O$ Oven-dried samples, $R$ Room temperature, and $F$ Freezing temperature higher than oven-dried samples with exception of LR at $t=2$ month and $t=3$ month. No differences were found in the case of the insoluble, soluble, and total fibre contents.

\section{Fatty acid profile}

The examination of the relative FA composition (as a percentage of the total FAs) shows important differences between oven-dried and freeze-dried A. taxiformis as well as variations over storage time-only the initial ( $t=0$ month) and final ( $t=3$ month) points are displayed (Table 2).

All FA profiles were characterized by a high weight of saturated FAs (SFA) - always exceeding $76 \%$ of the total FAs-, low levels of monounsaturated FAs (MUFA) $-4-11 \%$ of the total FAs - , and very low levels of PUFA
$-0-11 \%$ of the total FAs. The exception was freeze-dried A. taxiformis at $t=0$ month (11\% PUFA). The single most important FA was the palmitic acid (16:0), which varied between 57 and $72 \%$ of the total FAs. The myristic acid (14:0) was also important, being in the $16-18 \%$ range of the total FAs. The most important MUFA was the oleic acid $(18: 1 \omega 9)$ with $2-5 \%$ of the total FAs. The ARA was the main $\omega 6$ PUFA, but only displayed very low contents $(<2 \%$ of the total FAs). The same was observed for the total $\omega 6$ PUFA. Furthermore, EPA (20:5 $\omega 3)$ was also below $2 \%$ of the total FAs with exception of freeze-dried A. taxiformis at $t=0$ month, which contained $8.6 \pm 1.7 \%$ of the total FAs. The EPA content was lower in oven-dried seaweed at $t=0$ month and for all other samples, which means a reduction in the EPA content of freeze-dried 
Table 2 Fatty acid profile (in \% of total fatty acids) of Asparagopsis taxiformis subjected to different drying processes and storage conditions at the initial ( $t=0$ month) and final ( $t=3$ month) time of the storage stability experiment

\begin{tabular}{lclllll}
\hline $\begin{array}{l}\text { Fatty acid (\% } \\
\text { total fatty acids) }\end{array}$ & OR0/OF0 & LR0/LF0 & OR3 & OF3 & LR3 & LF3 \\
\hline $14: 0$ & $17.0 \pm 0.2^{\mathrm{a}}$ & $15.6 \pm 1.0^{\mathrm{a}}$ & $18.2 \pm 2.3^{\mathrm{a}}$ & $17.8 \pm 2.1^{\mathrm{a}}$ & $16.4 \pm 1.2^{\mathrm{a}}$ & $16.2 \pm 1.3^{\mathrm{a}}$ \\
$16: 0$ & $59.8 \pm 0.6^{\mathrm{ab}}$ & $57.1 \pm 2.3^{\mathrm{a}}$ & $66.8 \pm 1.3^{\mathrm{cd}}$ & $63.1 \pm 0.8^{\mathrm{bc}}$ & $71.8 \pm 3.6^{\mathrm{d}}$ & $69.5 \pm 1.5^{\mathrm{d}}$ \\
$18: 0$ & $1.3 \pm 0.0^{\mathrm{a}}$ & $1.3 \pm 0.0^{\mathrm{ab}}$ & $1.4 \pm 0.2^{\mathrm{abc}}$ & $1.3 \pm 0.1^{\mathrm{a}}$ & $1.7 \pm 0.0^{\mathrm{c}}$ & $1.6 \pm 0.2^{\mathrm{bc}}$ \\
$\Sigma$ SFA & $81.8 \pm 1.3^{\mathrm{ab}}$ & $76.2 \pm 3.2^{\mathrm{a}}$ & $88.1 \pm 1.0^{\mathrm{bc}}$ & $86.1 \pm 3.1^{\mathrm{bc}}$ & $93.1 \pm 3.8^{\mathrm{c}}$ & $89.2 \pm 1.8^{\mathrm{c}}$ \\
$16: 1 \omega 9$ & $1.9 \pm 0.1^{\mathrm{bc}}$ & $\mathrm{nd}^{\mathrm{a}}$ & $2.1 \pm 0.2^{\mathrm{c}}$ & $1.6 \pm 0.3^{\mathrm{b}}$ & $\mathrm{nd}$ & $\mathrm{nd}^{\mathrm{a}}$ \\
$17: 1$ & $0.6 \pm 0.0^{\mathrm{ab}}$ & $1.1 \pm 0.5^{\mathrm{ab}}$ & $0.2 \pm 0.4^{\mathrm{a}}$ & $0.4 \pm 0.4^{\mathrm{a}}$ & $0.7 \pm 0.7^{\mathrm{ab}}$ & $1.6 \pm 0.16^{\mathrm{b}}$ \\
$18: 1 \omega 9$ & $4.5 \pm 0.2^{\mathrm{a}}$ & $4.0 \pm 0.1^{\mathrm{ab}}$ & $3.6 \pm 0.3^{\mathrm{bc}}$ & $3.1 \pm 0.5^{\mathrm{cd}}$ & $2.8 \pm 0.3^{\mathrm{cd}}$ & $2.1 \pm 0.3^{\mathrm{d}}$ \\
$18: 1 \omega 7$ & $1.5 \pm 0.1^{\mathrm{ab}}$ & $2.1 \pm 0.4^{\mathrm{b}}$ & $1.2 \pm 0.1^{\mathrm{ab}}$ & $1.0 \pm 0.2^{\mathrm{a}}$ & $0.5 \pm 0.5^{\mathrm{a}}$ & $0.6 \pm 0.5^{\mathrm{a}}$ \\
$\Sigma$ MUFA & $11.0 \pm 0.4^{\mathrm{a}}$ & $9.8 \pm 1.5^{\mathrm{ab}}$ & $8.7 \pm 0.9^{\mathrm{ab}}$ & $7.7 \pm 0.9^{\mathrm{bc}}$ & $4.4 \pm 1.2^{\mathrm{d}}$ & $5.2 \pm 1.0^{\mathrm{cd}}$ \\
$20: 4 \omega 6$ & $0.5 \pm 0.1^{\mathrm{a}}$ & $1.7 \pm 0.4^{\mathrm{b}}$ & $\mathrm{nd}^{\mathrm{a}}$ & $0.2 \pm 0.2^{\mathrm{a}}$ & $0.1 \pm 0.1^{\mathrm{a}}$ & $\mathrm{nd}^{\mathrm{a}}$ \\
$20: 5 \omega 3$ & $1.9 \pm 0.2^{\mathrm{a}}$ & $8.6 \pm 1.7^{\mathrm{b}}$ & $0.3 \pm 0.6^{\mathrm{a}}$ & $0.7 \pm 0.7^{\mathrm{a}}$ & $0.3 \pm 0.3^{\mathrm{a}}$ & $1.0 \pm 0.9^{\mathrm{a}}$ \\
$\Sigma$ PUFA & $3.0 \pm 0.4^{\mathrm{a}}$ & $10.5 \pm 2.5^{\mathrm{b}}$ & $0.3 \pm 0.6^{\mathrm{a}}$ & $1.1 \pm 1.1^{\mathrm{a}}$ & $1.9 \pm 1.9^{\mathrm{a}}$ & $1.0 \pm 0.9^{\mathrm{a}}$ \\
$\Sigma \omega 3$ PUFA & $1.9 \pm 0.2^{\mathrm{a}}$ & $8.6 \pm 1.7^{\mathrm{b}}$ & $0.3 \pm 0.6^{\mathrm{a}}$ & $0.7 \pm 0.7^{\mathrm{a}}$ & $0.3 \pm 0.3^{\mathrm{a}}$ & $1.0 \pm 0.9^{\mathrm{a}}$ \\
$\Sigma \omega 6$ PUFA & $1.0 \pm 0.2^{\mathrm{ab}}$ & $1.9 \pm 0.9^{\mathrm{b}}$ & $\mathrm{nd}^{\mathrm{a}}$ & $0.3 \pm 0.3^{\mathrm{ab}}$ & $1.4 \pm 1.4^{\mathrm{ab}}$ & $\mathrm{nd}^{\mathrm{a}}$ \\
\hline
\end{tabular}

Values are presented as the average \pm standard deviation. $n d$ not detected. Different lowercase letters within a row correspond to significant differences $(p<0.05)$ between the relative $(\%)$ FA profiles of the seaweed samples

$L$ Freeze-dried samples, $O$ Oven-dried samples, $R$ Room temperature, and $F$ Freezing temperature samples over storage time regardless of storage temperature. The same pattern was observed for ARA. Oleic acid content declined over storage time regardless of drying process and storage temperature. On the other hand, palmitic acid increased over storage time (by 7 to $15 \%$ of the total FAs) with exception of oven-dried A. taxiformis stored at $-20{ }^{\circ} \mathrm{C}$.

\section{Total polyphenol content}

The determined values of polyphenol content in both aqueous and ethanolic extracts are shown in Table 3.

The variations observed in each group of extracts (aqueous $v s$ ethanolic) were clearly distinct. However, for both extract groups, phenolic content was higher in the freezedried samples at the beginning of the storage experiment and remained so until the end in the case of the ethanolic extracts. Moreover, in the aqueous extracts, phenolic contents increased for all samples (submitted to different drying and storage conditions) over storage time. This is clear in OF samples, where phenolic content increased from $93 \pm 4 \mathrm{mg} \mathrm{GAE} / 100 \mathrm{~g}$ dw to more than $140 \mathrm{mg} \mathrm{GAE} / 100 \mathrm{~g}$ dw after three month storage. The temporal evolution in the ethanolic extracts was opposite to that of the aqueous extracts, since their phenolic contents declined over storage time, being the reduction observed after the first month. These variations were quite similar. For instance, phenolic content in LR samples decreased from $94 \pm 4 \mathrm{mg}$ $\mathrm{GAE} / 100 \mathrm{~g} \mathrm{dw}$ to $64 \pm 2 \mathrm{mg} \mathrm{GAE} / 100 \mathrm{~g} \mathrm{dw}$ after three month storage.
Table 3 Total polyphenol contents (in mg GAE/100 g dry weight) of Asparagopsis taxiformis subjected to different drying processes and storage conditions at different times of the storage stability experiment

\begin{tabular}{clcccc}
\hline Sample & \multirow{2}{*}{$\begin{array}{l}\text { Time } \\
\text { (month) }\end{array}$} & \multicolumn{5}{c}{ Total polyphenol (mg GAE/100 g dw) } \\
\cline { 3 - 6 } & & OR & \multicolumn{1}{c}{ OF } & LR & LF \\
\hline Aqueous & 0 & $93 \pm 4^{\text {aw }}$ & $93 \pm 4^{\text {aw }}$ & $104 \pm 4^{\text {bw }}$ & $104 \pm 4^{\text {bw }}$ \\
extract & 1 & $101 \pm 3^{\text {awx }}$ & $101 \pm 4^{\text {aw }}$ & $105 \pm 4^{\text {aw }}$ & $108 \pm 3^{\text {aw }}$ \\
& 2 & $131 \pm 3^{\text {ay }}$ & $138 \pm 7^{\text {ax }}$ & $133 \pm 5^{\text {ax }}$ & $154 \pm 4^{\text {by }}$ \\
& 3 & $119 \pm 8^{\text {axy }}$ & $144 \pm 0^{\text {bx }}$ & $152 \pm 8^{\text {cy }}$ & $125 \pm 5^{\text {abx }}$ \\
Ethanolic & 0 & $75 \pm 1^{\text {aw }}$ & $75 \pm 1^{\text {aw }}$ & $94 \pm 4^{\text {bw }}$ & $94 \pm 4^{\text {bw }}$ \\
extract & 1 & $50 \pm 4^{\text {ax }}$ & $49 \pm 1^{\text {ax }}$ & $63 \pm 1^{\text {bx }}$ & $64 \pm 2^{\text {bx }}$ \\
& 2 & $47 \pm 1^{\text {ax }}$ & $47 \pm 1^{\text {ax }}$ & $69 \pm 3^{\text {bx }}$ & $67 \pm 2^{\text {bx }}$ \\
& 3 & $49 \pm 1^{\text {ax }}$ & $47 \pm 1^{\text {ax }}$ & $64 \pm 2^{\text {bx }}$ & $62 \pm 1^{\text {bx }}$ \\
\hline
\end{tabular}

Values are presented as the average \pm standard deviation. Different lowercase letters (a-d) within a row correspond to significant differences $(p<0.05)$ between the drying and storage conditions. Different lowercase letters $(\mathrm{w}-\mathrm{z})$ within a column correspond to significant differences $(p<0.05)$ over storage time for each type of extract

$L$ Freeze-dried samples, $O$ Oven-dried samples, $R$ Room temperature, and $F$ Freezing temperature

\section{Antioxidant activity}

The antioxidant activity determined by the DPPH and ABTS methods for both groups of extracts (aqueous and ethanolic) are presented in Tables 4 and 5, respectively.

Regarding DPPH results, as observed in the phenolic contents ("Total polyphenol content" Section), there were differences in the values and variations for each extract 
Table 4 DPPH antioxidant activity (in mg AA Eq/100 g dry weight) of Asparagopsis taxiformis subjected to different drying processes and storage conditions at different times of the storage stability experiment

\begin{tabular}{|c|c|c|c|c|c|}
\hline \multirow[t]{2}{*}{ Sample } & \multirow[t]{2}{*}{$\begin{array}{l}\text { Time } \\
\text { (month) }\end{array}$} & \multicolumn{4}{|c|}{$\begin{array}{l}\text { DPPH antioxidant activity (mg AA } \\
\text { Eq/100 g dw) }\end{array}$} \\
\hline & & $\overline{\mathrm{OR}}$ & OF & LR & $\mathrm{LF}$ \\
\hline \multirow[t]{4}{*}{ Aqueous extract } & 0 & $14 \pm 3^{\text {aw }}$ & $14 \pm 3^{\text {aw }}$ & $17 \pm 1^{\text {aw }}$ & $17 \pm 1^{\mathbf{a x}}$ \\
\hline & 1 & $24 \pm 0^{a x}$ & $21 \pm 1^{b \mathbf{x}}$ & $22 \pm 1^{\text {abx }}$ & $17 \pm 1^{\mathbf{c x}}$ \\
\hline & 2 & $32 \pm 0^{a x}$ & $38 \pm 1^{\text {by }}$ & $41 \pm 3^{\text {by }}$ & $43 \pm 2^{\text {by }}$ \\
\hline & 3 & $29 \pm 4^{\text {bx }}$ & $46 \pm 5^{\mathbf{c y}}$ & $22 \pm 3^{\text {abwx }}$ & $10 \pm 1^{\text {aw }}$ \\
\hline \multirow{4}{*}{$\begin{array}{c}\text { Ethanolic } \\
\text { extract }\end{array}$} & 0 & $52 \pm 1^{\text {aw }}$ & $52 \pm 1^{\text {aw }}$ & $34 \pm 1^{\text {bw }}$ & $34 \pm 1^{\mathrm{bw}}$ \\
\hline & 1 & $47 \pm 1^{a x}$ & $45 \pm 0^{\text {by }}$ & $33 \pm 1^{\mathrm{cw}}$ & $24 \pm 0^{\mathrm{dy}}$ \\
\hline & 2 & $45 \pm 0^{\text {ay }}$ & $46 \pm 0^{\operatorname{axy}}$ & $42 \pm 0^{\mathbf{b x}}$ & $32 \pm 0^{\mathbf{c x}}$ \\
\hline & 3 & $45 \pm 0^{\text {ay }}$ & $46 \pm 0^{a x}$ & $42 \pm 0^{\mathbf{b x}}$ & $35 \pm 1^{\mathrm{cw}}$ \\
\hline
\end{tabular}

Values are presented as the average \pm standard deviation. Different lowercase letters (a-d) within a row correspond to significant differences $(p<0.05)$ between the drying and storage conditions. Different lowercase letters $(\mathrm{w}-\mathrm{z})$ within a column correspond to significant differences $(p<0.05)$ over storage time for each type of extract

$L$ Freeze-dried samples, $O$ Oven-dried samples, $R$ Room temperature, and $F$ Freezing temperature

group. There were some strong oscillations, particularly in the aqueous extracts. For the latter, there was a clear growing trend in the case of the oven-dried samples, but stronger in the OF samples, which increased from $14 \pm 3 \mathrm{mg} \mathrm{AA}$

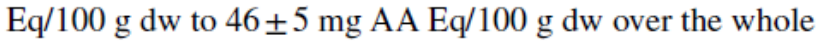
storage time. In the aqueous extracts of freeze-dried samples no such increase was observed and a reduction was registered for LF. With respect to the ethanolic extracts, variations were more modest, being detected a slight decreasing trend in the oven-dried seaweed regardless of storage temperature.
Concerning ABTS, aqueous and ethanolic extracts trended in the same direction, all showing strong increases over storage time with the sole exception of the ethanolic extracts of LR samples. More specifically, in the case of ethanolic extracts, freeze-dried A. taxiformis had always higher antioxidant activity than oven-dried seaweed. Indeed, whereas OR and OF samples presented ABTS values in the 0.26-1.18 mmol Trolox Eq/100 $\mathrm{g}$ dw range, LR and LF samples exhibited ABTS results in a clearly higher interval, 1.65-2.46 mmol Trolox Eq/100 g dw. An equivalent contrast in the case of aqueous extracts was absent due to the very steep increase of ABTS antioxidant activity of OF seaweed from $0.84 \pm 0.14 \mathrm{mmol}$ Trolox $\mathrm{Eq} / 100 \mathrm{~g}$ dw to $4.40 \pm 0.23 \mathrm{mmol}$ Trolox Eq/100 g dw, which was more than the double of OR at $t=3$ month, $2.13 \pm 0.05 \mathrm{mmol}$ Trolox $\mathrm{Eq} / 100 \mathrm{~g} \mathrm{dw}$. However, taking into account all storage temperature contrasts, this independent variable did not seem as influential as drying process and storage time.

\section{Anti-inflammatory activity}

The anti-inflammatory activity expressed as percentage of COX-2 inhibition and reflecting its response to the three independent variables of the experimental design (drying process, storage temperature, and storage time) is presented in Table 6. Moreover, after averaging OR, OF, LR, and LF samples, a more clear-cut dependence of anti-inflammatory activity on storage time is achieved and illustrated by Fig. 2 . Tested extract concentration was $1 \mathrm{mg} / \mathrm{ml}$.

At the beginning of the storage study, oven-dried samples displayed higher anti-inflammatory activity than freeze-dried samples, but differences between drying processes were progressively lost and were absent after three month storage. With respect to storage temperature, it was not possible to identify any unequivocal effect for the two
Table 5 ABTS antioxidant activity (in mmol Trolox $\mathrm{Eq} / 100 \mathrm{~g}$ dry weight) of Asparagopsis taxiformis subjected to different drying processes and storage conditions at different times of the storage stability experiment

\begin{tabular}{|c|c|c|c|c|c|}
\hline \multirow[t]{2}{*}{ Sample } & \multirow{2}{*}{$\begin{array}{l}\text { Time } \\
\text { (month) }\end{array}$} & \multicolumn{4}{|c|}{ ABTS antioxidant activity (mmol Trolox Eq/100 g dw) } \\
\hline & & OR & OF & LR & LF \\
\hline \multirow[t]{4}{*}{ Aqueous extract } & 0 & $0.84 \pm 0.14^{\text {aw }}$ & $0.84 \pm 0.14^{\mathrm{aw}}$ & $1.17 \pm 0.13^{\mathrm{aw}}$ & $1.17 \pm 0.13^{\text {aw }}$ \\
\hline & 1 & $2.37 \pm 0.24^{\mathrm{ax}}$ & $1.81 \pm 0.25^{\mathrm{bx}}$ & $2.11 \pm 0.06^{\mathrm{abx}}$ & $2.42 \pm 0.22^{\mathrm{ax}}$ \\
\hline & 2 & $2.17 \pm 0.15^{\mathrm{ax}}$ & $3.52 \pm 0.25^{\text {by }}$ & $2.67 \pm 0.40^{\mathrm{ax}}$ & $3.51 \pm 0.35^{\text {by }}$ \\
\hline & 3 & $2.13 \pm 0.05^{\mathrm{ax}}$ & $4.40 \pm 0.23^{\mathrm{cz}}$ & $2.50 \pm 0.10^{\mathrm{abx}}$ & $2.89 \pm 0.51^{\mathrm{bxy}}$ \\
\hline \multirow[t]{4}{*}{ Ethanolic extract } & 0 & $0.26 \pm 0.04^{\mathrm{aw}}$ & $0.26 \pm 0.04^{\mathrm{aw}}$ & $1.75 \pm 0.22^{\mathrm{bw}}$ & $1.75 \pm 0.22^{\mathrm{bw}}$ \\
\hline & 1 & $0.93 \pm 0.08^{\text {ay }}$ & $1.18 \pm 0.06^{\mathrm{ay}}$ & $2.33 \pm 0.18^{\mathbf{b x}}$ & $2.46 \pm 0.09^{\mathrm{bx}}$ \\
\hline & 2 & $0.62 \pm 0.06^{\mathrm{ax}}$ & $0.80 \pm 0.05^{\mathrm{bx}}$ & $1.65 \pm 0.35^{\mathrm{cw}}$ & $2.44 \pm 0.02^{\mathrm{dx}}$ \\
\hline & 3 & $0.75 \pm 0.06^{\mathrm{ax}}$ & $0.90 \pm 0.08^{\mathrm{ax}}$ & $1.67 \pm 0.03^{\mathrm{bw}}$ & $2.42 \pm 0.05^{\mathrm{cx}}$ \\
\hline
\end{tabular}

Values are presented as the average \pm standard deviation. Different lowercase letters (a-d) within a row correspond to significant differences $(p<0.05)$ between the drying and storage conditions. Different lowercase letters $(\mathrm{w}-\mathrm{z})$ within a column correspond to significant differences $(p<0.05)$ over storage time for each type of extract

$L$ Freeze-dried samples, $O$ Oven-dried samples, $R$ Room temperature, and $F$ Freezing temperature 
Table 6 Anti-inflammatory activity (\% inhibition of COX-2) in ethanolic extracts of Asparagopsis taxiformis subjected to different drying processes and storage conditions at different times of the storage stability experiment

\begin{tabular}{|c|c|c|c|c|c|}
\hline \multirow[t]{2}{*}{ Sample } & \multirow[t]{2}{*}{$\begin{array}{l}\text { Time } \\
\text { (month) }\end{array}$} & \multicolumn{4}{|c|}{$\begin{array}{l}\text { Anti-inflammatory activity (\% inhibition } \\
\text { of COX-2) }\end{array}$} \\
\hline & & OR & OF & LR & LF \\
\hline \multirow{4}{*}{$\begin{array}{c}\text { Ethanolic } \\
\text { extract }\end{array}$} & 0 & $29 \pm 7^{\text {aw }}$ & $29 \pm 7^{a w}$ & $6 \pm 3^{\text {bw }}$ & $6 \pm 3^{\text {bw }}$ \\
\hline & 1 & $20 \pm 5^{\mathrm{aw}}$ & $3 \pm 3^{\text {aw }}$ & $20 \pm 8^{\text {awx }}$ & $44 \pm 4^{\text {by }}$ \\
\hline & 2 & $15 \pm 3^{\text {aw }}$ & $26 \pm 6^{\mathrm{abw}}$ & $30 \pm 5^{b x y}$ & $32 \pm 7^{\text {bxy }}$ \\
\hline & 3 & $40 \pm 11^{a x}$ & $30 \pm 12^{\mathrm{aw}}$ & $40 \pm 7^{\text {ay }}$ & $26 \pm 4^{a x}$ \\
\hline
\end{tabular}

Values are presented as the average \pm standard deviation. Different lowercase letters (a-d) within a row correspond to significant differences $(p<0.05)$ between the drying and storage conditions. Different lowercase letters $(\mathrm{w}-\mathrm{z})$ within a column correspond to significant differences $(p<0.05)$ over storage time

$L$ Freeze-dried samples, $O$ Oven-dried samples, $R$ Room temperature, and $F$ Freezing temperature

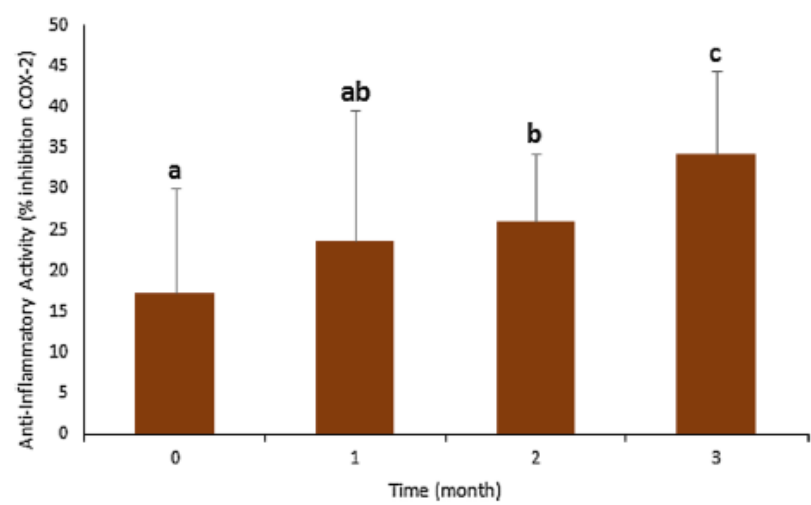

Fig. 2 Variation of the anti-inflammatory activity (\% inhibition of COX-2) in ethanolic extracts of Asparagopsis taxiformis over storage time. Each month value is the average of seaweed samples submitted to different drying and storage conditions. Different lowercase letters correspond to significant differences $(p<0.05)$ between different time points. Standard deviation is indicated by the vertical bars

pairs, OR vs OF and LR vs LF. However, after three month storage and averaging OR with LR as well as OF with LF, a significant $(p<0.05)$ difference was detected with a $12 \%$ additional activity in A. taxiformis at room temperature. A complex evolution of the anti-inflammatory capacity over time was observed with the exception of LR, which showed an almost continuous increase of the COX-2 inhibition from $t=0$ month $(6 \pm 3 \%)$ to $t=3$ month $(40 \pm 7 \%)$. However, if all OR, OF, LR, and LF values are combined for each sampled storage time (Fig. 2), an overall increasing trend is observed from the beginning to the second month and, finally, to the third month, thus doubling the initial value (17-34\% range).

\section{Discussion}

\section{Proximate composition and fibre content}

The proximate composition and fibre content values were stable over storage time and were not particularly sensitive to storage temperature. The drying method generated some differences, particularly in the case of the moisture and ash contents. Oven-drying $\left(60^{\circ} \mathrm{C}\right.$ for $\left.72 \mathrm{~h}\right)$ was more effective than freeze-drying $\left(-40^{\circ} \mathrm{C}\right.$ and $4 \times 10^{-4} \mathrm{mbar}$ for $48 \mathrm{~h}$ ) in removing moisture from A. taxiformis. As a probable consequence, ash contents were higher in the oven-dried seaweed. Such effect was missing in the case of the protein and lipid contents. A hypothetic explanation for the observed lower protein and lipid contents in oven-dried A. taxiformis could be the occurrence of dripping during the $72 \mathrm{~h}$ in the oven (during freeze-drying water remains frozen and no such dripping is possible). However, this explanation is weakened by the absence of a similar effect on the ash content. Finally, fibre content did not show any variation, not even a relative concentration-as occurred in the case of ash content-or lower values by dripping loss-as hypothesized for protein and lipid contents-in the oven-dried samples. Regarding this latter possibility, fibre (at least, the insoluble part) would be less prone to be lost, given its structural role in A. taxiformis biomass. Studies on other seaweed species showed some similarities. Namely, Chan et al. (1997) [26] reported a higher moisture level in freeze-dried Sargassum hemiphyllum when compared with the oven-dried seaweed. However, ash content in $S$. hemiphyllum was higher in freeze-dried samples, thus differing from the variations observed in A. taxiformis. More studies on this subject are necessary, given their current scarcity.

\section{Fatty acid profile}

There are not many studies on A. taxiformis. More specifically, concerning lipid fraction components, studies are scarcer. The current study is the first one to encompass drying and storage conditions and storage time for this seaweed species. There is a study on the FA profile of A. armata [27], which displays a composition similar to those of the current study. Indeed, palmitic acid content exceeded $50 \%$ of the total FAs and total SFA level surpassed $80 \%$ of the total FAs. Moreover, total MUFA was the second most important group and total PUFA content was very low, $4.7 \pm 0.4 \%$ of total FAs. ARA and EPA were the main $\omega 6$ and $\omega 3$ PUFA, respectively, just as in the current study. Specifically, EPA content was $2.9 \pm 0.2 \%$ of total FAs. All these FA levels agree with A. taxiformis 
results, which is probably a result of the taxonomic proximity and its influence on the FA composition. The biomass of A. armata was freeze-dried, thus a higher EPA content in freeze-dried A. taxiformis ( $t=0$ month) may probably be an interspecific difference. Nonetheless, even higher EPA contents are found for other red seaweeds [28-30]. An extreme example is the red seaweed Palmaria palmata (order Palmariales) with almost $70 \%$ EPA [28]. Moreover, the EPA content of red seaweeds has been found to depend on seasonality [30] and location [31].

The drying process is considered influential on EPA and PUFA contents, which are prone to oxidation and degradation [32, 33]. This may explain the lower ARA and EPA contents in oven-dried samples (OR and OF). A study on S. hemiphyllum [26] concluded that the nutritional composition of seaweed may be greatly affected by different drying methods, being total PUFA content higher in freezedried seaweed than in oven-dried seaweed.

Schmid et al. (2016) [34] investigated the effect of storage temperature and time on the stability of PUFA in ground and freeze-dried seaweed biomass. Samples were stored for a total duration of 22 months (with intermediate samplings after one and three months) at three different temperatures $\left(-20{ }^{\circ} \mathrm{C}, 4{ }^{\circ} \mathrm{C}\right.$, and $\left.20{ }^{\circ} \mathrm{C}\right)$. For the red seaweed $P$. palmata, levels of ARA, EPA, and PUFA were only stable after storage at $-20{ }^{\circ} \mathrm{C}$. This observation differed from current study, where this same temperature did not prevent loss of these FAs after three month storage. However, species are different and initial levels also differed between $P$. palmata and A taxiformis. At $20{ }^{\circ} \mathrm{C}$, there was some loss of EPA and PUFA after one month storage, which became massive after 22 month storage [34]. As in current study, palmitic acid content increased over storage time at $20^{\circ} \mathrm{C}$ as well as at $4{ }^{\circ} \mathrm{C}$.

In general, it is considered that lipid degradation by oxidation is a major concern during storage of dried biological materials. Lipid oxidation may take place by different mechanisms, such as autoxidation, photosensitized or enzymatic oxidation [35]. Autoxidation is a free radical chain reaction encompassing initiation, propagation, and termination steps. In the initiation step a spontaneous abstraction of hydrogen of the FA by oxygen occurs. When the hydrogen atom is attached to carbon atoms between two double bonds, its dissociation energy is low, leading to FA radicals. This entails that PUFAs are more susceptible to oxidation [35]. Though the initiation step is an endothermic reaction that requires substantial activation energy [35], even at $-20{ }^{\circ} \mathrm{C}$ this did not prevent PUFA loss in A. taxiformis biomass. The increase of palmitic acid content may be at least partially ascribed to the mathematical consequences of a relative decline in the proportion of other FAs.

\section{Total polyphenol content}

The variation of the phenolic contents in aqueous and ethanolic extracts in opposite directions over storage time suggest a possible conversion of less hydrophilic (soluble in ethanol) phenolic compounds into more hydrophilic ones. Since the phenolic contents reported in the relevant literature for a biomass rich in these compounds range from 100 to $500 \mathrm{mg} \mathrm{GAE} / 100 \mathrm{~g} \mathrm{dw}$ [36], the aqueous extracts of A. taxiformis may be considered a satisfactory source of phenolic substances. It is important to remark that a number of intrinsic factors can affect the concentration of phenolic compounds, namely the geographical location, climate, and phase of algal ripening at harvest, being claimed that higher phenolic contents in seaweed are associated with higher UV exposure [37].

Seaweed drying is considered a process that may decrease phenolic content either by binding polyphenols with other compounds (e.g. proteins) or by altering the chemical structure of polyphenols [38]. These biochemical alterations are accelerated by a higher drying temperature. This seems to corroborate results at $t=0$ month. Moreover, Le Lann et al. (2008) [14] analysed the effects of sun-drying $(72 \mathrm{~h})$, oven-drying $\left(50-60^{\circ} \mathrm{C}, 40 \mathrm{~h}\right)$, and freeze-drying $(72 \mathrm{~h}$ ) on the biomass quality of Sargassum muticum and Bifurcaria bifurcata. These authors reported that phenolic content was higher in freeze-dried samples than in oven-dried samples. Similar results were also found by Wong and Cheung (2001) [39] for three brown Sargassum species. A decline of phenolic content by $28 \%$ in red seaweed Porphyra sp. after oven-drying has also been described [17]. In contrast, Ling et al. (2015) [40] observed for methanolic extracts of the red seaweed Kappaphycus alvarezii a higher phenolic content in oven-dried samples $\left(80^{\circ} \mathrm{C}, 24 \mathrm{~h}\right)$ compared to freeze-dried seaweed.

It may be conjectured a relationship between phenolic content in ethanolic extracts-more lipophilic phenolic substances- and PUFA contents (in \% of total FAs). Indeed, it is known that PUFAs are more prone to oxidation than SFAs and MUFAs [41] — see also "Fatty acid profile" Section. Phenolic compounds constitute a possible response due to their antioxidant properties. Lipophilic phenolics are even more important since they can easily mingle with lipid molecules and position themselves near the FAs of phospholipids. Accordingly, a decline in phenolic content of the ethanolic extracts due to oven-drying or prolonged storage may entail a lower protection of PUFA against oxidation. In fact, it was found a consistent trend when total phenolic content in the ethanolic extracts was related to EPA (a very susceptible PUFA with five double bonds) content $\left(R^{2}=0.8\right)$. 


\section{Antioxidant activity}

With respect to the effect of the drying process, Le Lann et al. (2008) [14] found significantly higher activity as measured by DPPH in the freeze-dried samples compared to oven-dried samples. These authors claimed that the heat generated by the oven probably induced some denaturation of phenolic compounds that hampered their bioactivity. On the other hand, Ling et al. (2015) [40], on the basis of DPPH and ABTS results, stated that oven-dried $\left(80^{\circ} \mathrm{C}\right)$ samples of $K$. alvarezii displayed stronger scavenging activity and reducing ability as compared to tested freeze-dried samples. Such findings seem to contradict the thermal degradative effect on phenolic substances and other antioxidants. However, as mentioned in "Total polyphenol content" Section, this study [40] had measured a higher phenolic content in oven-dried samples. Moreover, studies on brown seaweeds $[42,43]$ have observed an overall strengthening of the antioxidant capacity and a substantial increase in the phenolic content with exposure to higher temperatures. Of course, this is not the reason for the higher DPPH activity of the ethanolic extracts attained from oven-dried A. taxiformis, since phenolic content in these extracts was lower than in those from freeze-dried samples. Hence, this subject warrants further study.

Concerning the storage study, variation of DPPH in some samples and of ABTS in almost all samples over time was opposite to what would be expected in a scenario of progressive loss of quality of the A. taxiformis biomass. Though such evolution is uncommon, it is not unparalleled. Indeed, a stability study on plant material using hydroalcoholic extracts by Montoro et al. (2006) [44] reported that after three month storage antioxidant activity increased relative to that of the initial time, while the major antioxidants' content declined. Conversion of some of these compounds into others that are more bioactive was a possible explanation. The same may have happened in the current study on $A$. taxiformis and the increase of the concentration of phenolic substances in the aqueous extracts over storage time while concentration in the ethanolic extracts declined may be an indication of such conversion phenomena.

There was divergence in the antioxidant activity as determined by different methodologies. Such divergence reflects the relative strengthening of the antioxidant activity as measured by ABTS with respect to the DPPH methodology. Considering that applied techniques are not equivalent and reflect different antioxidant properties, such lack of consistency could be expected. In fact, ABTS has been considered more sensitive than DPPH, usually yielding different results [45].

Neither DPPH nor ABTS values show any degree of correlation with the total polyphenol content. This suggests that each phenolic compound may have a different impact on antioxidant activity as measured by DPPH or ABTS. This warrants further study directed to the analysis of the phenolic profile of A. taxiformis. Moreover, other compounds in this seaweed species, such as carotenoids [9], may exert a role in generating antioxidant activity.

\section{Anti-inflammatory activity}

The anti-inflammatory activity of seaweed is still poorly studied and the assay techniques vary, comprising in vitro tests and in vivo models [46-48]. This causes difficulties whenever comparisons across studies are made. Nevertheless, there are studies pointing to the existence of antiinflammatory bioactives in seaweed $[49,50]$ and substantial bioactivity in red seaweed [47]. This latter study reported that an ethanol extract from Gracilaria verrucosa showed anti-inflammatory activity as measured in astrocyte cell cultures. Kim et al. (2013) [51] observed in an in vitro study that floridoside, a natural glycerol galactoside naturally isolated from the red seaweed Laurencia undulata, was able to suppress pro-inflammatory responses in microglia by markedly inhibiting the production of nitric oxide and reactive oxygen species. The methods used in these studies were different from that used in the current study, in which the activity of the COX-2 enzyme was reduced by inhibition. Furthermore, sometimes different solvents were used in the preparation of the extracts of other studies. It should be remarked that a preliminary study with the initial samples ( $t=0$ month) of $A$. taxiformis showed that anti-inflammatory activity was more significant in the ethanolic extracts of $A$. taxiformis. Hence, for all samples, ethanolic extracts were prepared and anti-inflammatory activity measured in them. One of the few studies using the COX-2 activity inhibition methodology was carried out for green seaweed and used aqueous extracts [52]. These authors found anti-inflammatory activity in $10 \%$, w/v, extracts, the residue of which was dissolved in DMSO (1 mg/ml): COX-2 inhibition varied between 31 and $45 \%$, which is relatively similar to the results attained with the A. taxiformis ethanolic extracts. Campos et al. (2019) [53] also used the COX-2 inhibition method and observed anti-inflammatory activity in aqueous extracts of the brown seaweed Petalonia binghamiae $(40 \pm 7 \%$ inhibition). For the red seaweed Osmundea pinnatifida, according to the same study, neither aqueous nor ethanolic extracts generated anti-inflammatory activity.

Whereas the drying process and storage temperature did not drive clear changes in the levels of anti-inflammatory activity of A. taxiformis ethanolic extracts, a global effect of storage time on anti-inflammatory activity was observed and indicated an enhancement of this property (Fig. 2). As with the antioxidant activity, this differs from the most usual outcome of biomass quality loss. An explanation may lie in the nature of the compounds generating the anti-inflammatory 
activity. Indeed, different classes of compounds may have anti-inflammatory effects, phenolic compounds, carotenoids, phytosterols, alkaloids or polysaccharides. Though $\omega 3$ PUFA and, particularly, EPA display an anti-inflammatory action [12] these compounds do not inhibit COX-2. Moreover, there was no strong correlation between the total phenolic content and anti-inflammatory activity. Thus, anti-inflammatory activity in A. taxiformis extracts may be the result of different compounds, necessarily soluble in ethanol, which excludes polysaccharides given their low solubility in ethanol. Therefore, other compounds, such as carotenoids and phytosterols, may underlie the observed anti-inflammatory activity and conversion phenomena during storage time may have generated more bioactive molecules.

Acknowledgements This study was supported by the following Grants: Ref.: SFRH/BPD/102689/2014 ("Fundação para a Ciência e a Tecnologia", FCT) for Carlos Cardoso, DIVERSIAQUA (MAR2020, Ref.: 16-02-01-FEAM-66) for Cláudia Afonso, and (SFRH/ BD/129795/2017; FCT) for Joana Matos. The experimental work was funded by the projects AQUAMAX (Ref.: 16-02-01-FMP-0047), I9 + PROALGA (Ref.: 16-01-03-FMP-0011), and FCT (Ref.: UID/ AGR/04129/2019).

\section{Compliance with ethical standards}

Conflict of Interest There is no conflict of interest involving any of the authors.

Compliance with ethics requirements This article does not contain any studies with human or animal subjects.

\section{References}

1. Algaebase (2018) Global algal database of taxonomic, nomenclatural and distributional information. https://www.algaebase. org/search/species/detail/?species_id=636\&sk=0\&from $=$ resul ts. Accessed 19 Sept 2018

2. Pereira L (2015) Seaweed flora of the European North Atlantic and Mediterranean. In: Kim S-K (ed) Springer handbook of marine biotechnology. Springer Verlag, Berlin, pp 65-178

3. Roque B, Brooke C, Ladau J, Polley T, Marsh L, Najafi N, Pandey P, Singh L, Kinley R, Salwen J, Eloe-Fadrosh E, Kebreab E, Hess M (2019) Effect of the macroalgae Asparagopsis taxiformis on methane production and rumen microbiome assemblage. Anim Microbiome 1(4):1-14

4. Smith PM, Bustamante H, Ahammad H, Clark H, Dong EA, Elsiddig H, Haberl R, Harper J, House M, Jafari O, Masera C, Mbow NH, Ravindranath CW, Rice C, Robledo Abad A, Romanovskaya F, Sperling F, Tubiello F (2013) Agriculture, forestry and other land use (AFOLU). In: Edenhofer O, Pichs-Madruga R, Sokona Y, Farahani E, Kadner S, Seyboth K, Adler A, Baum I, Brunner S, Eickemeier P, Kriemann B, Savolainen J, Schlömer S, von Stechow C, Zwickel T, Minx JC (eds) Climate change: mitigation of climate change contribution of working group III to the fifth assessment report of the intergovernmental panel on climate change. Cambridge University Press, Cambridge, New York, pp $811-922$
5. Maeda H (2013) Anti-obesity and anti-diabetic activities of algae. In: Domínguez H (ed) Functional ingredients from algae for foods and nutraceuticals. Woodhead Publishing Limited, Oxford, pp $453-472$

6. Pirian K, Moein S, Sohrabipour J, Rabiei R, Blomster J (2017) Antidiabetic and antioxidant activities of brown and red macroalgae from the Persian Gulf. J Appl Phycol 29(6):3151-3159

7. Oumaskour K, Boujaber N, Etahiri S, Assobhei O (2013) Antiinflammatory and antimicrobial activities of twenty-three marine red algae from the Coast of Sidi Bouzid (E1 Jadida-Morocco). Int J Pharm Pharmaceut Sci 5(3):145-149

8. Nunes N, Ferraz S, Valente S, Barreto C, Pinheiro de Carvalho MAA (2017) Biochemical composition, nutritional value, and antioxidant properties of seven seaweed species from Madeira archipelago. J Appl Phycol 29(5):2427-2437

9. Ragonese C, Tedone L, Beccaria M, Torre G, Cichello F, Cacciola F, Dugo P, Mondello L (2014) Characterisation of lipid fraction of marine macroalgae by means of chromatography techniques coupled to mass spectrometry. Food Chem 145:932-940

10. Mellouk Z, Benammar I, Krouf D, Goudjil M, Okbi M, Malaisse W (2017) Antioxidant properties of the red alga Asparagopsis taxiformis collected on the North West Algerian coast. Exp Ther Med 13(6):3281-3290

11. Simopoulos AP (2002) Omega-3 fatty acids and cardiovascular disease: the epidemiological evidence. Environ Health Prev Med 6:203-209

12. Tanaka N, Ishida T, Nagao M, Mori T, Monguchi T, Sasaki M, Mori K, Kondo K, Nakajima H, Honjo T, Irino Y, Toh R, Shinohara M, Hirata K (2014) Administration of high dose eicosapentaenoic acid enhances anti-inflammatory properties of high-density lipoprotein in Japanese patients with dyslipidemia. Atherosclerosis 237(2):577-583

13. Gupta S, Cox S, Abu-Ghannam N (2011) Effect of different drying temperatures on the moisture and phytochemical constituents of edible Irish brown seaweed. LWT Food Sci Technol 44(5):1266-1272

14. Le Lann K, Jégou C, Stiger-Pouvreau V (2008) Effect of different conditioning treatments on total phenolic content and antioxidant activities in two Sargassacean species: comparison of the frondose Sargassum muticum (Yendo) Fensholt and the cylindrical Bifurcaria bifurcata R Ross. Phycol Res 56(4):238-245

15. Kadam U, Álvarez C, Tiwari B, Donnell CPO (2015) Processing of seaweeds. In: Tiwari BK, Troy DJ (eds) Seaweed sustainability: food and non-food applications. Academic Press, Amsterdam, The Netherlands, pp 61-78

16. Stévant P, Rebours C, Chapman A (2017) Seaweed aquaculture in Norway: recent industrial developments and future perspectives. Aquacult Int 25(4):1373-1390

17. Jiménez-Escrig A, Jiménez-Jiménez I, Pulido R, Saura-Calixto F (2001) Antioxidant activity of fresh and processed edible seaweeds. J Sci Food Agric 81(5):530-534

18. Le Gall L, Saunders GW (2010) DNA Barcoding is a powerful tool to uncover algal diversity: a case study of the Phyllophoraceae (Gigartinales, Rhodophyta) in the Canadian flora. J Phycol 46:374-389

19. AOAC (2000) Official methods of analysis of the AOAC International, 17th edn. Association of Analytical Communities, Gaithersburg

20. Saint-Denis T, Goupy J (2004) Optimization of a nitrogen analyser based on the Dumas method. Anal Chim Acta 515(1):191-198

21. Folch J, Lees M, Sloane Stanley GH (1957) A simple method for the isolation and purification of total lipids from animal tissues. $\mathrm{J}$ Biol Chem 226:497-509

22. Bandarra NM, Batista I, Nunes ML, Empis JMA, Christie WW (1997) Seasonal changes in lipid composition of sardine Sardina pilchardus. J Food Sci 62(1):40-43 
23. Singleton VL, Rossi JA (1965) Colorimetry of total phenolics with phosphomolybdic-phosphotungstic acid reagents. Am J Enol Viticul 16:144-158

24. Miliauskas G, Venskutonis PR, Van Beek TA (2004) Screening of radical scavenging activity of some medicinal and aromatic plant extracts. Food Chem 85:231-237

25. Re R, Pellegrini N, Proteggente A, Pannala A, Yang M, RiceEvans C (1999) Antioxidant activity applying an improved ABTS radical cation decolorization assay. Free Radical Biol Med 26:1231-1237

26. Chan JC-C, Cheung PC-K, Ang PO (1997) Comparative studies on the effect of three drying methods on the nutritional composition of seaweed Sargassum hemiphyllum (Turn ) C Ag. J Agric Food Chem 45(8):3056-3059

27. Pereira H, Barreira L, Figueiredo F, Custódio L, Vizetto-Duarte C, Polo C, Rešek E, Engelen A, Varela J (2012) Polyunsaturated fatty acids of marine macroalgae: Potential for nutritional and pharmaceutical applications. Marine Drugs 10(9):1920-1935

28. Graeve M, Kattner G, Wiencke C, Karsten U (2002) Fatty acid composition of Arctic and Antarctic macroalgae: indicator of phylogenetic and trophic relationships. Mar Ecol Prog Ser 231:67-74

29. Mouritsen OG, Dawczynski C, Duelund L, Jahreis G, Vetter W, Schröder M (2013) On the human consumption of the red seaweed dulse (Palmaria palmata (L ) Weber, Mohr). J Appl Phycol 25(6):1777-1791

30. Schmid M, Guihéneuf F, Stengel DB (2014) Fatty acid contents and profiles of 16 macroalgae collected from the Irish coast at two seasons. J Appl Phycol 26(1):451-463

31. Munier M, Dumay J, Morancais M, Jaouen P, Fleurence J (2013) Variation in the biochemical composition of the edible seaweed Grateloupia turuturu Yamada harvested from two sampling sites on the Brittany Coast (France): the influence of storage method on the extraction of the seaweed pigment R-phycoerythrin. J Chem. https://doi.org/10.1155/2013/568548

32. Schmid M, Guihéneuf F, Stengel DB (2017) Ecological and commercial implications of temporal and spatial variability in the composition of pigments and fatty acids in five Irish macroalgae. Mar Biol 164(8): 158

33. Turan A (2018) Effect of drying methods on fatty acid profile and oil oxidation of hazelnut oil during storage. Eur Food Res Technol 244(12):2181-2190

34. Schmid M, Guihéneuf F, Stengel DB (2016) Evaluation of food grade solvents for lipid extraction and impact of storage temperature on fatty acid composition of edible seaweeds Laminaria digitata (Phaeophyceae) and Palmaria palmata (Rhodophyta). Food Chem 208:161-168

35. Choe E, Min DB (2006) Mechanisms and factors for edible oil oxidation. Compr Rev Food Sci Food Saf 5(4):169-186

36. Farasat M, Khavari-Nejad RA, Nabavi SMB, Namjooyan F (2013) Antioxidant properties of two edible green seaweeds from northern coasts of the Persian Gulf Jundishapur. J Nat Pharm Prod $8(1): 47-52$

37. Bischof K, Gómez I, Molis M, Hanelt D, Karsten U, Lüder U, Roleda MY, Zacher K, Wiencke C (2006) Ultraviolet radiation shapes seaweed communities. Rev Environ Sci Bio/Technol $5(2 / 3): 141$

38. Mrad ND, Boudhrioua N, Kechaou N, Courtois F, Bonazzi C (2012) Influence of air drying temperature on kinetics, physico-
40. Ling ALM, Yasir S, Matanjun P, Bakar MFA (2015) Effect of different drying techniques on the phytochemical content and antioxidant activity of Kappaphycus alvarezii. J Appl Phycol 27(4):1717-1723

41. Tao L (2015) Oxidation of polyunsaturated fatty acids and its impact on food quality and human health. Adv Food Technol Nutr Sci Open J 1(6): 135-142

42. Norra I, Aminah A, Suri R, Zaidi JA (2017) Effect of drying temperature on the content of fucoxanthin, phenolic and antioxidant activity of Malaysian brown seaweed Sargassum sp. J Trop Agric Food Sci 45(1):25-36

43. Rajauria G, Kumar A, Abu-Ghannam N, Gupta S (2010) Effect of hydrothermal processing on colour, antioxidant and free radical scavenging capacities of edible Irish brown seaweeds. Int J Food Sci Technol 45:2485-2493

44. Montoro P, Tuberoso CIG, Piacente S, Perrone A, De Feo V, Cabras P, Pizza C (2006) Stability and antioxidant activity of polyphenols in extracts of Myrtus communis $\mathrm{L}$ berries used for the preparation of myrtle liqueur. J Pharm Biomed Anal 41(5):1614-1619

45. Martysiak-Żurowska D, Wenta W (2012) A comparison of ABTS and DPPH methods for assessing the total antioxidant capacity of human milk Acta Scientiarum Polonorum Technologia. Alimentaria 11(1):83-89

46. Jin DQ, Lim CS, Sung JY, Choi HG, Ha I, Han JS (2006) Ulva conglobata, a marine algae, has neuroprotective and anti-inflammatory effects in murine hippocampal and microglial cells. Neurosci Lett 402:154-158

47. Montalvão S, Demirel Z, Devi P, Lombardi V, Hongisto V, Perälä M, Hattara J, Imamoglu E, Tilvi SS, Turan G, Dalay MC, Tammela P (2018) Large-scale bioprospecting of cyanobacteria, micro- and macroalgae from the Aegean Sea. New Biotechnol 33(3):399-406

48. Yang EJ, Moon JY, Kim MJ, Kim DS, Lee WJ, Lee NH, Hyun CG (2010) Anti-inflammatory effect of Petalonia binghamiae in LPS-induced macrophages is mediated by suppression of iNOS and COX-2. Int J Agric Biol Eng 12(5):754-758

49. Pangestuti R, Vo TS, Ngo DH, Kim SK (2013) Fucoxanthin ameliorates inflammation and oxidative responses in microglia. J Agric Food Chem 61(16):3876-3883

50. Wong CH, Gan SY, Tan SC, Gany SA, Ying T, Gray AI, Igoli J, Chan EWL, Phang SM (2018) Fucosterol inhibits the cholinesterase activities and reduces the release of pro-inflammatory mediators in lipopolysaccharide and amyloid-induced microglial cells. J Appl Phycol 30(6):3261-3270

51. Kim M, Li YX, Dewapriya P, Ryu B, Kim SK (2013) Floridoside suppresses pro-inflammatory responses by blocking MAPK signaling in activated microglia. BMB Reports 46(8):398-403

52. Ripol A, Cardoso C, Afonso C, Varela J, Quental-Ferreira H, Pousão-Ferreira P, Bandarra NM (2018) Composition, antiinflammatory activity, and bioaccessibility of green seaweeds from fish pond aquaculture. Nat Prod Commun 13(5):603-608

53. Campos AM, Matos J, Afonso C, Gomes R, Bandarra NM, Cardoso C (2019) Azorean macroalgae (Petalonia binghamiae, Halopteris scoparia and Osmundea pinnatifida) bioprospection: a study of fatty acid profiles and bioactivity. Int J Food Sci Technol 54(3):880-890 